\title{
Development of management abilities of motor transportation companies' leaders
}

\author{
Nadezhda I. Chernetskaya ${ }^{1, *}$, Elena A. Kedyarova ${ }^{2}$, Vera V. Monzhievskaya ${ }^{3}$, and Margarita Yu. Uvarova ${ }^{4}$ \\ ${ }^{1}$ Irkutsk State University, 30-14, Mayakovsky Str., Angarak, Russia \\ ${ }^{2}$ Irkutsk State University, 39-8, Komsomolskaya Str., Irkutsk, Russia \\ ${ }^{3}$ Irkutsk State University, 42-2, Rosa Luxemburg Str., Irkutsk, Russia \\ ${ }^{4}$ Irkutsk State University, 27-312, 25 ${ }^{\text {th }}$ of October Str., Irkutsk, Russia
}

\begin{abstract}
The paper presents main ways of development of management abilities of motor transportation companies' leaders. Summary of modern investigations devoted to development of management abilities in made. Peculiarities of management abilities is motor-transportation branch are shown. The study devoted to personal traits of motor transportation leaders that can be a factor of their better quality and higher effectiveness at work is done and its results are presented. It was proved that several personal traits give the basis of a better quality at work of motor transportation leaders: activity, communicativeness, persistence, stress tolerance, purposefulness, and absence of the role conflict at work. These traits and qualities can be taken as a basis when we decide to develop management abilities of motor transportation leaders. At the particular motor transportation company in Irkutsk (Siberia region) where the investigation was done the majority of leaders have these traits and qualities at much lower level than it is required. As a result, the developing program for them was proposed. This program included the description of conditions on which the developing work can be done effectively and the content of the developing work itself. The proposed and tested program consists of four blocks including developing, modelling and correcting psychological technologies that taken in common had shown a significant shift of management abilities of motor transportation leaders.
\end{abstract}

Keywords: management abilities, transportation companies' leaders, personal traits, qualities, role conflict

\section{Introduction}

The XXI century is the time when not only high technologies, but also highly qualified leaders in all branches are required. Some decades ago, high qualifications meant mainly the education and the experience in the branch, but today it is not the way - the personal traits and qualities and good management abilities among them are the main point of high qualification. Management abilities and personal traits and qualities related to them give a significant reason for promotions and for professional success. In the transportation branch that grows and changes every day effective leadership is one of the most important issues to study and to develop.

The problem of development of management abilities was taken into consideration and was studied many times [1-3], but not in relation to personal traits and qualities and not in the field of motor transportation branch as much as it is required and as we have shown in our previous publications $[10,11]$.

\section{Problem Statement}

The applied point if this research is related to the particular case in Irkutsk: a general manager of the motor transportation company made a request upon the investigation of his employees that do management work and hold managerial duties. He characterized them as highly qualified specialists in their field but not effective enough leaders. These managers mostly understand that they are not quite good at their leadership at work, they have a fear to lose their posts and, as a result, they are under stress almost all the work-time. Recruiting new managers is not the best solution in this case because this branch has very specific demands upon employees and it is not easy to find many qualified motor transportation specialists who are ready to come into the company. The same problem is stated constantly in publications such as: Druker P.F. (2004), Erina S.I. (2009), Gerasimov B.N. (2017), Gornakova N.S., Uvarova M.YU. (2018), Ogorodnikov A.Y., Przhlenskaya I.B. (2019), Pfeffer J. (2015), Savelyev I.I., Mekhdiev S.Z. (2017), Zhuravleva I.I. (2017). Researchers confirm that nowadays leaders are highly qualified, but have poor leadership and management abilities.

So the request turned into a study of personal traits and qualities of motor transportation company leaders that determined their leadership's effectiveness, and as a result the program of development of management abilities of these employees was prepared and tested.

* Corresponding author: cherna@yandex.ru 


\section{Research Questions}

1. The first point of the study was to make a theoretical analysis of the researches done upon the subject of the study and to see what developmental methods are used for leadership development.

2. The second point of the study was to find personal traits and qualities that can be taken as indexes of management abilities of motor transportation company leaders.

3. The third and the main point of the study was to prepare a program for motor transportation company leaders to develop their management abilities in a short time period.

\section{Purpose of the Study}

The aim of the study was to make a research of management abilities of motor transportation leaders, to prepare a developing program for them and to prove its effectiveness.

\section{Research Methods}

The following empirical methods were used: perceptive detection of stress-tolerance, diagnostics of communicative and management abilities with the 'KOS-2' test, diagnostics of leadership orientations by T. Santalayen, diagnostics of the role conflict by S. Erina.

The following mathematical and statistical methods were used: Wilcoxon Rank-Sum Test, Mann-Whitney U-test.

\section{Findings}

\subsection{Indexes of management abilities and their correlation}

The first index of management abilities was stress tolerance, and it appeared to be low in the sample of the motor transportation company leaders. $17 \%$ of them have a type A stress tolerance, they are very motivated to success and use all possible means to achieve it but also they are constantly unsatisfied by themselves and by their life circumstances, so sometimes they can be aggressive and not patient. They are highly active; they have a high verbal indexes and very strong subverbal signals that can cause problems both with their colleagues and with administration. Only $42 \%$ of leaders have a high level of these qualities. $4.17 \%$ have an extremely low level of these qualities. These test subjects felt uncomfortable during testing, were suspicious about the research especially about the point whether this testing was related to administrative check, they wanted to finish the testing as soon as possible. They were not interested about the results of the testing; they did not have questions about it and were disagreeing about some point of the research.

Leadership orientations' testing has shown that the majority of leaders (more than $75 \%$ ) were oriented to the task. That orientation was good from the point of view of corporative culture, corporative values of this motor transportation company. This company is very orientated to the value of time, success and motivation. But also $17 \%$ of leaders of the company did not show any orientation in leadership. It means that these leaders cannot set tasks; they do not have strong goals and cannot organize collective work of other employees.

The role conflict testing let us define the group of leaders $(8.3 \%)$ that demonstrated a high level of role conflict. They are very much under stress about being leaders and about their responsibility at work. They want to be leaders and they mostly like their job but they hate the responsibility and they suffer from work stress. It makes their everyday work stressful and hard for them mainly because of constant necessity to control them.

After counting averages of management abilities' indexes, we defined two groups of motor transportation company leaders: group 1 - leaders with high management abilities and group 2 - leaders with low management abilities (later this group was also divided into two samples - experimental and control groups). Results of the comparison are presented in figure 1 .

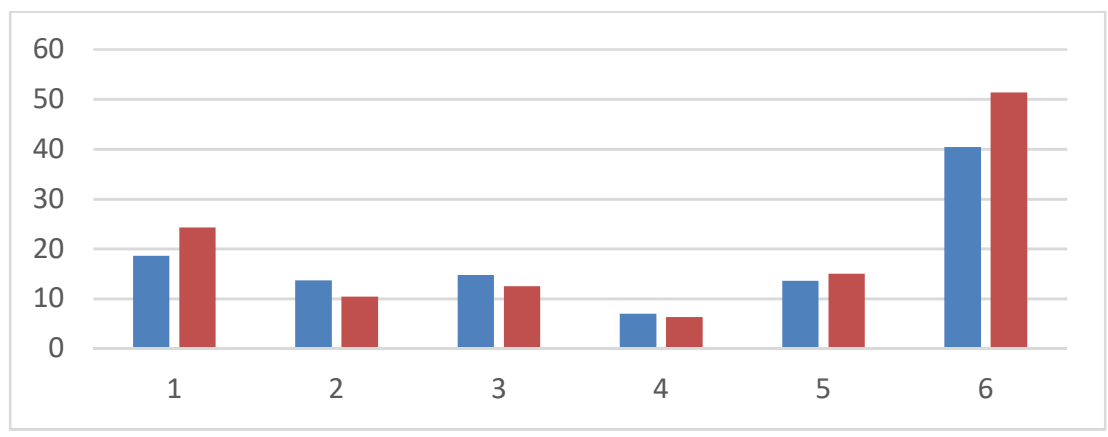

Legend: blue - group 1, red - group 2

1 - stress tolerance indexes of A-type

2 - communicative abilities

3 - organizational skills

4 - orientation for people

5 - orientation for work tasks

6 - role conflict indexes

Figure 1. Ratio of indicator of management abilities of motor transportation company leaders of groups 1 and 2 (averages) 


\subsection{Developing program to increase management abilities of motor transportation company leaders}

The program was developed on the basis of the results of the diagnostics described above. The program consisted of four parts. Each of them was focused on a particular index of management abilities of motor transportation leaders. It is presented in table 1.

\subsection{Efficiency marks of the developing program}

The program has shown the high level of efficiency upon all indexes of management abilities - all of them at a certain point are higher in the experimental group than that in the control group.

By means of Wilcoxon Rank-Sum Test we found out that changes that took place in the experimental group after the developing program were statistically significant for the perceptive level of stress tolerance, communicative and organizational skills, role conflict level. The indexes are presented in table 2.

Table 1. The program of development of management abilities of motor transportation company leaders

\begin{tabular}{|c|c|c|c|}
\hline No. & Time & Topics & Comments \\
\hline \multicolumn{4}{|c|}{ Part 1 Leadership and goal setting } \\
\hline 1 & $10: 00-10: 30$ & Introduction & Greetings, presentation of topics \\
\hline 2 & $10: 30-11: 00$ & Mini-lection & Management abilities \\
\hline 3 & $11: 00-11: 15$ & Coffee break & \\
\hline 4 & $11: 15-12: 05$ & $\begin{array}{c}\text { Leadership and } \\
\text { management }\end{array}$ & $\begin{array}{c}\text { Leaders and manager terminology, developing leadership } \\
\text { exercises }\end{array}$ \\
\hline 5 & $12: 05-12: 30$ & Mini-lection & 'Why it is important to set priorities to achieve goals' \\
\hline 6 & $12: 30-13: 00$ & Goal setting & Goal setting exercises \\
\hline 7 & $13: 00-14: 00$ & Lunch break & \\
\hline 8 & $14: 00-14: 30$ & Mini-lection & SMART-tasks \\
\hline 9 & $14: 30-15: 00$ & Training & Technologies of working with SMART-tasks \\
\hline 10 & $15: 00-16: 00$ & Conclusion & Feedback and concluding exercises \\
\hline \multicolumn{4}{|c|}{ Part 2 Communication } \\
\hline 1 & $10: 00-10: 30$ & Introduction & Greetings, presentation of topics \\
\hline 2 & $10: 30-11: 00$ & Mini-lection & Communicative and organizational skills \\
\hline 3 & $11: 00-11: 15$ & Coffee break & \\
\hline 4 & $11: 15-13: 00$ & $\begin{array}{c}\text { Communication } \\
\text { development }\end{array}$ & Communication training \\
\hline 5 & $13: 00-14: 00$ & Lunch break & \\
\hline 6 & $14: 00-15: 15$ & Teaching movie & Watching the movie 'Convince and win' \\
\hline 7 & $15: 15-16: 00$ & Conclusion & Discussing the movie and the feedback \\
\hline \multicolumn{4}{|c|}{ Part 3 Forming the role of the leader } \\
\hline 1 & $10: 00-10: 30$ & Introduction & Greetings, presentation of topics, introductory exercise \\
\hline 2 & $10: 30-11: 00$ & Mini-lection & Self-esteem \\
\hline 3 & $11: 00-11: 15$ & Coffee break & \\
\hline 4 & $11: 15-13: 00$ & Confident leadership & Training of self-confidence \\
\hline 5 & $13: 00-14: 00$ & Lunch break & \\
\hline 6 & $14: 00-15: 00$ & Conclusion & Concluding exercises and the feedback \\
\hline \multicolumn{4}{|c|}{ Part 4 Stress tolerance } \\
\hline 1 & 10:00-10:30 & Introduction & Greetings, presentation of topics, introductory exercises \\
\hline 2 & $10: 30-11: 00$ & Mini-lection & 'How to avoid distress' \\
\hline 3 & $11: 00-11: 15$ & Coffee break & \\
\hline 4 & $11: 15-13: 00$ & Stress tolerance & $\begin{array}{c}\text { Exercises to increase stress tolerance, learning and training } \\
\text { relaxation techniques }\end{array}$ \\
\hline 5 & $13: 00-14: 00$ & Lunch break & \\
\hline 6 & $14: 00-15: 10$ & Stress tolerance & Training techniques with self-control and relaxation \\
\hline 7 & $15: 10-1600$ & Conclusion & The feedback and conclusion \\
\hline
\end{tabular}

Table 2. Significance indexes of differences between management abilities of motor transportation company leaders before and after the developing program on the basis of Wilcoxon Rank-Sum Test

\begin{tabular}{|c|c|c|c|c|c|c|}
\hline Significance & $\begin{array}{c}\text { Stress } \\
\text { tolerance }\end{array}$ & $\begin{array}{c}\text { Communicative } \\
\text { skills }\end{array}$ & $\begin{array}{c}\text { Organizational } \\
\text { skills }\end{array}$ & $\begin{array}{c}\text { Orientation } \\
\text { for people }\end{array}$ & $\begin{array}{c}\text { Orientation for } \\
\text { work tasks }\end{array}$ & $\begin{array}{c}\text { Role } \\
\text { conflict }\end{array}$ \\
\hline $\mathrm{Z}$ & $-2.214 \mathrm{~b}$ & $-1.826 \mathrm{c}$ & $-2.070 \mathrm{c}$ & $-1.841 \mathrm{~b}$ & $-1.826 \mathrm{c}$ & $-2.207 \mathrm{~b}$ \\
\hline $\begin{array}{c}\text { Asymptote } \\
\text { 2-ways significance }\end{array}$ & 0.027 & 0.068 & 0.038 & 0.066 & 0.068 & 0.027 \\
\hline
\end{tabular}

Legend: $\mathrm{b}-$ on the basis of positive ranking; $\mathrm{c}-$ on the basis of negative ranking 
As it can be seen from the data, the given perceptive level of stress tolerance of the A-type was lower in the experimental group while in the control group with time it even was higher. Maybe due to the tasks leaders of this group were working on while others were in the experiment made their stress tolerance even higher than at the very beginning.

Communicative and organizational skills in the experimental group got higher while in the control group they stayed at the same level as at the very beginning, organizational skills on some reason was even lower than they were before. It gives us a reason to assert that our developing program was effective for the experimental group leaders.
Comparing the results in experimental and control groups, we can also assert that the average level of orientation for people in the experimental group got lower while the average level of orientation for work tasks got higher. The leaders of the experimental group became more confident in their decisions; they are not that much under the fear of being wrong as they were before the program. In the control group, the orientation for people did not change and the orientation for work tasks was even lower that in was before which means they were still very much more worried about relationships and about approval than about their work. The role conflict level in the experimental group became lower.

All the indexes are presented in table 3 .

Table 3. Significance indexes of differences between management abilities of motor transportation company leaders before and after the developing program in experimental and control groups on the basis of Mann-Whitney U-test and Wilcoxon Rank-Sum Test

\begin{tabular}{|c|c|c|c|c|c|c|c|c|c|c|c|c|}
\hline Stat. test & ST & ST & Com & Com & Org & Org & OP & OP & OWT & OWT & RC & RC \\
\hline $\begin{array}{c}\text { Mann- } \\
\text { Whitney U-test }\end{array}$ & 17.000 & 12.500 & 4.500 & 3.000 & 16.000 & 9.000 & 17.000 & 15.500 & 14.500 & 11.000 & 15.000 & 8.000 \\
\hline $\begin{array}{c}\text { Wilcoxon } \\
\text { Rank-Sum } \\
\text { Test }\end{array}$ & 38.000 & 33.500 & 25.500 & 24.000 & 37.000 & 30.000 & 38.000 & 36.500 & 35.500 & 32.000 & 36.000 & 29.000 \\
\hline $\mathrm{Z}$ & -0.160 & -0.889 & -2.189 & -2.423 & -0.324 & -1.478 & -0.166 & -0.419 & -0.565 & -1.139 & -0.481 & -1.604 \\
\hline $\begin{array}{c}\text { Asymptote } \\
\text { 2-ways } \\
\text { significance }\end{array}$ & 0.873 & 0.374 & 0.029 & 0.015 & 0.746 & 0.139 & 0.868 & 0.675 & 0.572 & 0.255 & 0.630 & 0.109 \\
\hline $\begin{array}{c}\text { Precise } \\
\text { significance }\end{array}$ & $0.937 \mathrm{~b}$ & $0.394 \mathrm{~b}$ & $0.026 \mathrm{~b}$ & $0.015 \mathrm{~b}$ & $0.818 \mathrm{~b}$ & $0.180 \mathrm{~b}$ & $0.937 \mathrm{~b}$ & $0.699 \mathrm{~b}$ & $0.589 \mathrm{~b}$ & $0.310 \mathrm{~b}$ & $0.699 \mathrm{~b}$ & $0.132 \mathrm{~b}$ \\
\hline
\end{tabular}

Legend: ST - perceptive level of stress tolerance; OP - orientation for people; Com. - communicative skills; OWT - orientation for work tasks; Org. - organizational skills; RC - role conflict. b - not corrected for correlation

\section{Conclusion}

After analyzing the theoretical material around the point of management abilities the main definition of it was specified: management abilities are complex abilities to set goals, develop strategies and plans but also abilities to communicate and organize people of different social, gender, educational and psychological categories to make them work in the same vector.

Studying peculiarities of work of motor transportation company's leaders, we concluded that their work is full of stress and high tension; it is multifunctional and can be done only when they are focused of work tasks.

Taking management abilities' development as its improvement we created and realized a program for motor transportation company leaders. This program was built on the basis of psychological conditions of management abilities of leaders; personal traits and work orientations were taken as main conditions above the others. During the study we divided our leaders' sample into two parts - with high management abilities and with low management abilities and the second one were later used for an experimental and control groups.

After mathematical analysis we concluded that among other indexes used to estimate the effectiveness of the program the following indexed got significantly better: stress tolerance, communicative and organizational skills, and the role conflict at work. It gave us a reason to assert that our developing program was effective and can be used in similar transportation companies to make management abilities of their leaders better.

\section{References}

1. J. Arevalo, R. Laud, M. Johnson. Managerial skills, mindsets, and roles: advancing taxonomy to relevancy and practicality. J. Acad. of Manag. Proc. (2014)

2. K. Blanshar. Leadership: going to the highest points of success (Piter Press, St. Petersburg, 2011)

3. S.A. Bobinkin. Correlation between management abilities and individual traits of personality in work or line leaders. St. Peter. Univ. Bull., 12(3), Part II, 17-21 (2009)

4. S.I. Erina, B.S. Lisovenko. Question of creativity in the situation of role conflict. Costr. Univ. Bull., 15, 114-117 (2009)

5. B.N. Gerasimov. Game modelling of the process of development and working out strategic decisions in organizations. Econ. and busin.: theory and pract., 4(1), 57-64 (2017)

6. N.S. Gornakova, M.Yu. Uvarova. Development of stress tolerance of station duty officers in 
psychological counselling. Proceedings of XVII scientific conference (Irkutsk, April 2018, Irkutsk State University) (2018), pp. 196-201

7. A.Y. Ogorodnikov, I.B. Przhlenskaya. Basics of management (Publ. House Rusines, Moscow, 2018)

8. J. Pfeffer. Leadership: Fixing Workplaces and Careers One Truth at a Time (HarperCollins, New York, 2015)

9. I.I. Savelyev, S.Z. Mekhdiev. Personnel management: basics of management in the aspect of organizational behavior. (Rusline, Moscow, 2017)

10. E.A. Sukneva, E.A. Kedyarova, N.I Chetnetskaya. Development of leadership qualities of future civil employees. Pedag. Image. 13(2(43)), 240-250 (2019)

11. M.Yu. Uvarova, V.B. Rekoslavskaya. Study of management abilities of civil servants at motor transportation companies. Material of the XVIII scientific conference (Irkutsk, 25-26 April 2019, Irkutsk State University) (2019), pp. 253-257

12. I.I. Zhuravleva. Forming and developing management. Busin. Ed. in econ. of knowl., 1(6), 38-44 (2017) 